\title{
Changes of daily surface ozone maxima in Switzerland in all seasons from 1992 to 2002 and discussion of summer 2003
}

\author{
C. Ordóñez ${ }^{1}$, H. Mathis ${ }^{1}$, M. Furger ${ }^{1}$, S. Henne ${ }^{1}$, C. Hüglin ${ }^{2}$, J. Staehelin ${ }^{3}$, and A. S. H. Prévôt ${ }^{1}$ \\ ${ }^{1}$ Laboratory of Atmospheric Chemistry, Paul Scherrer Institut, CH-5232 Villigen, Switzerland \\ ${ }^{2}$ Swiss Federal Laboratories for Materials Testing and Research, Überlandstr. 129, CH-8600 Dübendorf, Switzerland \\ ${ }^{3}$ Institute for Atmospheric and Climate Science, ETH-Hönggerberg, CH-8093 Zürich, Switzerland
}

Received: 14 September 2004 - Published in Atmos. Chem. Phys. Discuss.: 2 November 2004

Revised: 24 January 2005 - Accepted: 21 March 2005 - Published: 25 May 2005

\begin{abstract}
An Analysis of Covariance (ANCOVA) was used to derive the influence of the meteorological variability on the daily maximum ozone concentrations at 12 low-elevation sites north of the Alps in Switzerland during the four seasons in the 1992-2002 period. The afternoon temperature and the morning global radiation were the variables that accounted for most of the meteorological variability in summer and spring, while other variables that can be related to vertical mixing and dilution of primary pollutants (afternoon global radiation, wind speed, stability or day of the week) were more significant in winter. In addition, the number of days after a frontal passage was important to account for ozone build-up in summer and ozone destruction in winter. The statistical model proved to be a robust tool for reducing the impact of the meteorological variability on the ozone concentrations. The explained variance of the model, averaged over all stations, ranged from $60.2 \%$ in winter to $71.9 \%$ in autumn. The year-to-year variability of the seasonal medians of daily ozone maxima was reduced by $85 \%$ in winter, $60 \%$ in summer, and $50 \%$ in autumn and spring after the meteorological adjustment. For most stations, no significantly negative trends (at the $95 \%$ confidence level) of the summer medians of daily $\mathrm{O}_{3}$ or $\mathrm{O}_{\mathrm{x}}\left(\mathrm{O}_{3}+\mathrm{NO}_{2}\right)$ maxima were found despite the significant reduction in the precursor emissions in Central Europe. However, significant downward trends in the summer 90th percentiles of daily $\mathrm{O}_{\mathrm{x}}$ maxima were observed at 6 sites in the region around Zürich (on average $-0.73 \mathrm{ppb} \mathrm{yr}^{-1}$ for those sites). The lower effect of the titration by NO as a consequence of the reduced emissions could partially explain the significantly positive $\mathrm{O}_{3}$ trends in the cold seasons (on average $0.69 \mathrm{ppb} \mathrm{yr}^{-1}$ in winter and $0.58 \mathrm{ppb} \mathrm{yr}^{-1}$ in autumn). The increase of $\mathrm{O}_{\mathrm{x}}$ found for most stations in autumn (on average $0.23 \mathrm{ppb} \mathrm{yr}^{-1}$ ) and winter (on average $0.39 \mathrm{ppb} \mathrm{yr}^{-1}$ ) could be due to increasing European background ozone lev-
\end{abstract}

Correspondence to: A. S. H. Prévôt

(andre.prevot@psi.ch) els, in agreement with other studies. The statistical model was also able to explain the very high ozone concentrations in summer 2003, the warmest summer in Switzerland for at least $\sim 150$ years. On average, the measured daily ozone maximum was $15 \mathrm{ppb}$ (nearly 29\%) higher than in the reference period summer 1992-2002, corresponding to an excess of 5 standard deviations of the summer means of daily ozone maxima in that period.

\section{Introduction}

It is well known that nitrogen oxides $\left(\mathrm{NO}_{\mathrm{x}}=\mathrm{NO}+\mathrm{NO}_{2}\right)$, volatile organic compounds (VOCs) and carbon monoxide (CO) react in the presence of sunlight to yield ozone $\left(\mathrm{O}_{3}\right)$ and other photo-oxidants in the troposphere. During the summer months, under stable weather conditions, the concentrations of near-surface ozone can reach high levels, causing harm to human health, to vegetation, and to materials. Surface ozone concentrations at European rural and remote sites increased by more than a factor of two from the late the 1950s until the early 1990s (Staehelin et al., 1994) because of the large increase in the emissions of ozone precursors in Europe and in the industrialised world during this period. Tropospheric $\mathrm{O}_{3}$ is also a direct greenhouse gas. The past increase in tropospheric $\mathrm{O}_{3}$ is estimated to provide the third largest increase in direct radiative forcing since the pre-industrial era (Ehhalt et al., 2001; Ramaswamy et al., 2001).

During the 1990s there have been continuous efforts to understand the mechanisms of photochemical smog formation in Europe and in Switzerland. For example, the POLLUMET (Air Pollution and Meteorology in Switzerland) project improved the knowledge about the spatial and temporal dynamics of the $\mathrm{VOC} / \mathrm{NO}_{\mathrm{x}}$ sensitivity of the ozone production in the Swiss Plateau for typical summer conditions (e.g. Dommen et al., 1995, 1999). The mechanisms of photo-oxidant formation are better known and various measures taken in

(C) 2005 Author(s). This work is licensed under a Creative Commons License. 
Switzerland and the neighbouring countries have led to a considerable decrease in emissions of ozone precursors. As an example the EMEP expert emission inventory estimates a decrease of the total emissions of $39 \%$ for $\mathrm{NO}_{\mathrm{x}}$ and $49 \%$ for non-methane volatile organic compounds (NMVOC) in Switzerland during the 1990-2002 period (Vestreng et al., 2004). However, near-surface ozone concentrations have apparently not decreased accordingly. Some studies have investigated data from the Swiss air pollution monitoring network (NABEL) to address the changes in ozone and primary pollutants in Switzerland since the mid-80s. Kuebler et al. (2001) used the Kolmogorov-Zurbenko filter $\mathrm{KZ}_{m, p}$ (Zurbenko, 1991; Rao et al., 1997) to remove the long-term trend, as well as a mean year to remove the seasonal and weekly variations. This allowed the use of meteorological variables to detrend the short-term variation of ozone and primary pollutants at 12 NABEL stations in the 1985-1998 period. The detrended summer (May-October) mean concentrations of primary pollutants presented a downward trend at urban and suburban stations. The $\mathrm{NO}_{\mathrm{x}}$ decrease reached about $50 \%$ at Zürich over a 12-year period and over $40 \%$ at Dübendorf during a 10-year period, though a smaller decrease (13\% in 9 years) was observed at Lugano. VOC levels at Zürich and Dübendorf showed a clear downward trend of around $50 \%$ over a 12 -year period. In contrast to the urban primary pollutants, the detrended 90th percentile summer ozone did not show any statistically significant trend at either the urban or rural sites. Brönnimann et al. (2002) used different methods to address changes in the ozone levels at 14 NABEL stations from 1991 to 1999 . They observed a considerable increase of the deseasonalised monthly mean ozone concentrations $\left(0.5-0.9 \mathrm{ppb} \mathrm{yr}^{-1}\right)$ together with a decrease in frequency of the low ozone concentrations. This study also suggested a tendency for decreasing ozone peaks under summer (April-September) smog days at rural sites and increasing ozone concentrations at the polluted sites north of the Alps.

Both the TOR-2 (Tropospheric Ozone Research) subproject of the EUROTRAC-2 (Transport and Transformation of Environmentally-Relevant Trace Constituents in the Troposphere over Europe) project and the TROTREP (Tropospheric Ozone and Precursors, Trends, Budgets and Policy) project evaluated the long term trends in ozone, oxidants and precursors in relation to the changes in emissions over Europe occurring after 1980 for various parts of Europe (Roemer, 2001a, b; Monks et al., 2003; TOR-2, 2003). For that purpose, some well-known methods were considered to remove the short-term and long-term variations in ozone caused by the meteorological influence: the already mentioned Kolmogorov-Zurbenko filtering followed by a regression method applied on one of the selected scales, clustering techniques applied to atmospheric circulation classes or according to decision trees to adjust the records for interannual shifts in the circulation or meteorological records, as well as methods based on multiple linear and non-linear regression models that incorporate a set of meteorological explaining variables (TOR-2, 2003). The results generally suggested that the precursor concentrations at urban sites decreased significantly since the mid-1980s or the beginning of the 1990s, mostly because of the successful introduction of catalytic converters in the European petrol vehicle fleet. Furthermore, it was concluded that the ozone precursor emission reductions that took place in North West Europe and Alpine Europe over the 90s were responsible for the ozone downward trends observed in the higher percentiles of the summer distribution. They also attributed the upward trends of low ozone concentrations observed in the polluted areas of $\mathrm{Eu}-$ rope at least partly to the reduced effect of the ozone titration by NO (Roemer, 2001a; Monks et al., 2003; TOR-2, 2003). An increase in the background concentrations of ozone was also found in the western and northern part of Europe (Roemer, 2001b; Monks et al., 2003; TOR-2, 2003). In addition, links between ozone and the NAO indices were documented to be most pronounced in the UK: summer ozone concentrations increased with the low NAO regime and decreased with the high NAO regime, compared to the mean ozone levels (Monks et al., 2003).

A variety of statistical approaches have been used for the meteorological adjustment of ozone and the estimation of ozone time trends in regional networks of ozone monitors at different locations of North America. Some of those studies modelled separately the association between each ozone monitor and local meteorology (Cox and Chu, 1996; Joe et al., 1996), while the most complex analyses derived a univariate summary of the ozone monitoring network to capture regional associations between ozone and meteorology (Bloomfield et al., 1996; Davis et al., 1998). Thompson et al. (2001) presented a critical review of those methods and compared the application of selected methods to ozone time series from the Chicago area.

This work reports on the meteorological adjustment and seasonal trends of daily ozone maxima at low-elevation sites in Switzerland during the 1992-2002 period. Section 2 describes the data used in this study and Sect. 3 presents the meteorological adjustment of the daily maximum ozone concentrations by statistical modelling of the relation between ozone concentrations and various meteorological variables. The results of the statistical analysis and the calculated trends are discussed in Sect. 4. These results are also compared to those of other slightly different statistical approaches. The meteorological adjustment of daily ozone maxima during the period summer 1992-2002 is extrapolated to summer 2003 in Sect. 5 , in order to test if the model is able to explain the very high ozone concentrations registered in that unusually warm and dry summer. Finally, Sect. 6 summarises our findings. 
Table 1. Stations used in the analysis. See location of the stations in Fig. 1.

\begin{tabular}{|c|c|c|c|c|}
\hline Station code & Station name & Altitude (m a.s.l.) & Station type & $\mathrm{NO}_{\mathrm{X}}(\mathrm{ppb})$ \\
\hline BAS & Basel & 320 & suburban & 11.61 \\
\hline DUE & Dübendorf & 430 & suburban & 15.57 \\
\hline HAE & Härkingen & 430 & rural/highway & 58.88 \\
\hline LAE & Lägeren $^{(a)}$ & 690 & rural/forest & 7.61 \\
\hline LAU & Lausanne & 530 & urban/street & 79.13 \\
\hline PAY & Payerne & 490 & rural & 6.28 \\
\hline SIO & Sion & 480 & rural/highway & 26.6 \\
\hline TAE & Tänikon & 540 & rural & 7.69 \\
\hline ZUE & Zürich-Kaserne & 410 & urban/park & 20.49 \\
\hline WAL & Wallisellen & 470 & suburban & 12.83 \\
\hline STA & Zürich-Stampfenbach & 445 & urban/street & 38.81 \\
\hline WEE & Weerswilen $^{(b)}$ & 630 & rural & - \\
\hline
\end{tabular}

WAL, STA and WEE are OSTLUFT stations. The other 9 stations belong to the NABEL network.

The $\mathrm{NO}_{\mathrm{X}}$ concentrations in this table correspond to the median of the afternoon averaged $\mathrm{NO}_{\mathrm{x}}$ levels during the 1992-2002 period.

(a) $\mathrm{No} \mathrm{NO}_{\mathrm{x}}$ data at Lägeren during the period 22 February-31 October 2000.

(b) $\mathrm{No} \mathrm{NO}_{\mathrm{x}}$ measurements at Weerswilen.
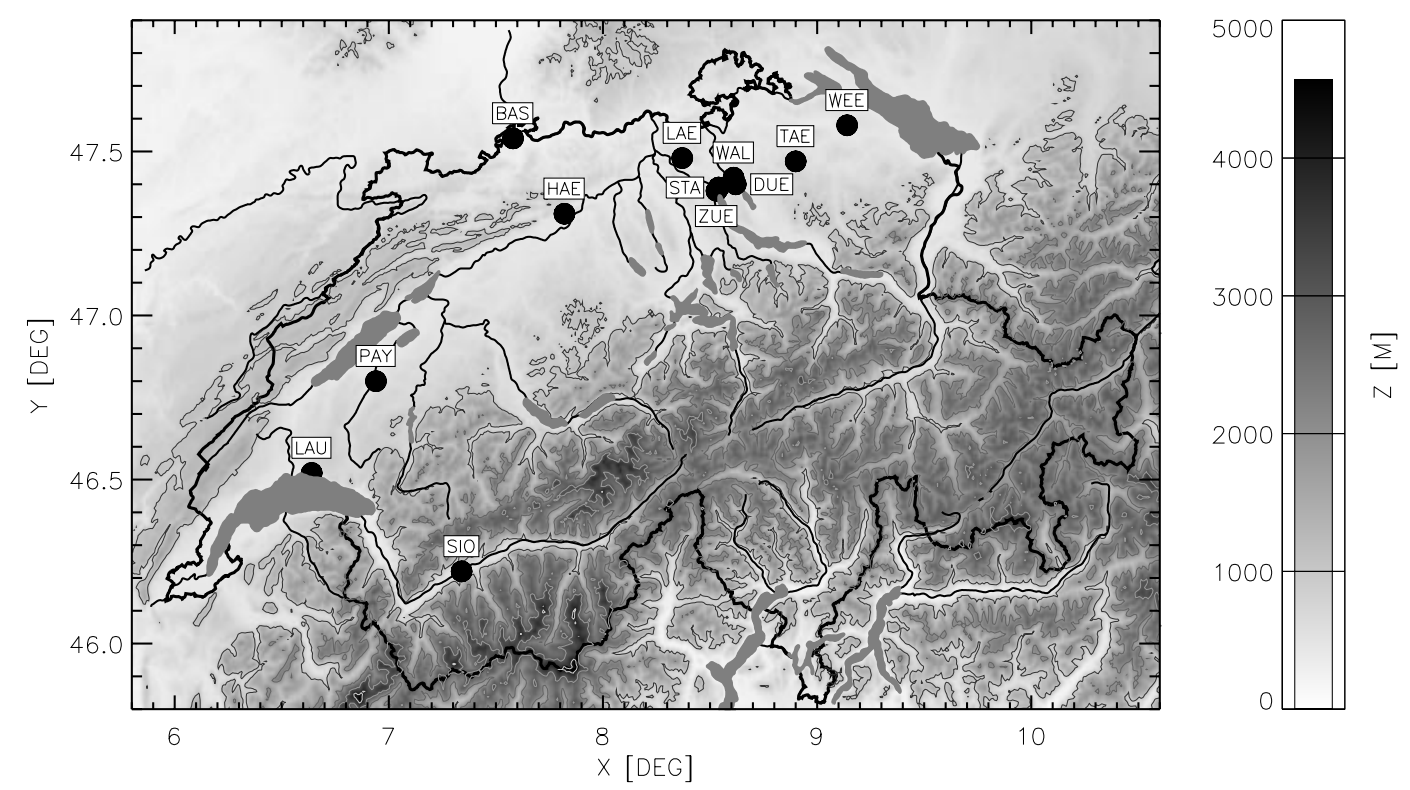

Fig. 1. Location of the stations used in the analysis. See the correspondence between codes and names of the stations in Table 1.

\section{Data}

\subsection{Ozone and $\mathrm{NO}_{\mathrm{x}}$ measurements}

Hourly average concentrations of ozone and nitrogen oxides from 12 low-elevation sites of the Swiss air quality monitoring network (NABEL) and the eastern cantons of Switzerland (OSTLUFT) during the period 1 January 1990 to 31 August 2003 were used in this study. The names and location of the analysed stations are summarised in Table 1 and Fig. 1. Except Sion, situated in an alpine valley, the sites are located in the Swiss plateau north of the Alps. At all stations, ozone was measured with the UV absorption method and nitrogen oxides $\left(\mathrm{NO}_{\mathrm{x}}\right)$ were detected by ozone chemiluminescence. $\mathrm{NO}$ was directly measured while $\mathrm{NO}_{2}$ was first reduced to NO with a molybdenum converter. The ozone and $\mathrm{NO}_{\mathrm{x}}$ monitors were calibrated automatically every 1-3 days and manually every 2-4 weeks. In addition, the ozone instruments were calibrated every three months with a standard reference photometer, and the molybdenum converter efficiency was examined once a year with gas phase titration (GPT). For more details on data quality assurance of the NABEL 
stations see EMPA (2003). Rigorous checks of the ozone and $\mathrm{NO}_{\mathrm{x}}$ data - i.e. analysis of the deviations of the concentrations measured at close stations and taking into account the changes in the location of the stations - confirmed that the data quality after 1991 was good for all the sites. Similar results were found in Brönnimann et al. (2002). Therefore, the time series of ozone for the 1992-2002 period were analysed in this work.

In this work we analyse the influence of the meteorology on the daily ozone maxima. These maximum concentrations usually occur in the afternoon and are the least affected by local NO sources reacting with ozone to nitrogen dioxide. However, at the most polluted stations (e.g. Lausanne and Härkingen) and under more polluted conditions (e.g. winter), the effect of the titration on the daily ozone maxima and hence on their trends can be important. To assist in the interpretation of the results the trends of $\mathrm{O}_{\mathrm{x}}$ (sum of $\mathrm{O}_{3}$ and $\mathrm{NO}_{2}$ ) were also calculated. $\mathrm{O}_{\mathrm{x}}$ is not influenced by the reaction of ozone with NO. However, as mentioned above, the $\mathrm{NO}_{2}$ measurements were performed with molybdenum converters, which exhibit interfering sensitivity to peroxyacyl nitrates (PANs), nitric acid $\left(\mathrm{HNO}_{3}\right)$ and other products of the oxidation of $\mathrm{NO}_{\mathrm{x}}$. The $\mathrm{NO}_{2}$ measurements and therefore the $\mathrm{O}_{\mathrm{x}}$ concentrations are thus upper limits of the real concentrations.

In this analysis, the daily $\mathrm{O}_{3}$ and $\mathrm{O}_{\mathrm{x}}$ maxima were defined as the daily maximum 1-h concentrations measured between 12:00 and 24:00 winter local time (UTC+1 h), and were calculated only if at least 9 values ( $75 \%$ of the data) were available for the respective day.

\subsection{Meteorological data}

Local meteorological data used as explanatory variables in a multiple linear model (see Sect. 3) were taken from the measuring NABEL sites and from the closest ANETZ stations operated by MeteoSwiss in the case of the OSTLUFT stations. The parameters sunshine duration and lightning, not measured at the NABEL network, were always taken from the surrounding ANETZ stations. In our analysis we attempt to select explanatory variables to represent the most important processes that influence ozone in the planetary boundary layer (PBL): in situ photochemical production, deposition and vertical mixing. The main parameters measured at those stations are temperature, global radiation, wind speed, wind direction and relative humidity. The morning ( $6 \mathrm{~h}$ to $12 \mathrm{~h}$ ) and/or afternoon ( $12 \mathrm{~h}$ to $18 \mathrm{~h}$ ) averages of those meteorological parameters were calculated when at least 5 out of the 6 hourly values ( $83 \%$ of the data) were available on the respective day.

Under typical summer smog conditions, the daily maximum ozone concentrations and temperature are strongly correlated. Several statistical models have been suggested to describe the increase in the ozone concentrations with ambient air temperature. Among others, models linear in temperature after some temporal filtering of both ozone and the meteorological variables (Kuebler et al., 2001; Tarasova and Karpetchko, 2003), a second or higher order polynomial in temperature (Brönnimann et al., 2002; Bloomfield et al., 1996) or linear regression of the logarithm of daily ozone maxima with daily maximum temperature as a categorical variable (Xu et al., 1996) have been proposed. Scatterplots of the daily ozone maxima against the different meteorological variables used in the analysis suggested that, at least in summer and spring, the afternoon temperature had the strongest relationship to ozone. Moreover, the dependence of ozone on temperature was more quadratic than linear. Therefore, both the afternoon temperature and the square of the afternoon temperature (preceded by a minus sign in the cases when the temperature is negative) have been tested in this study for every station and season. For simplicity, the one which was able to explain more variance was included in the initial model together with the rest of the meteorological variables. The averaged global radiation in the morning and in the afternoon have been used, as solar radiation is the main driver of the photochemical reactions and also affects the vertical mixing and thus the dilution of the pollutants, leading to lower ozone destruction. The sunshine duration is another parameter that can be used for the analysis of the influence of the solar radiation on the ozone concentrations. It is defined as the time during which the direct solar radiation exceeds the level of $120 \mathrm{~W} / \mathrm{m}^{2}$. The hourly fraction in which this value is exceeded was measured at the surrounding ANETZ stations, and both the morning and afternoon averages of this parameter were calculated. The morning and afternoon wind speeds were also used, as these parameters influence the dilution and transport of pollutants. The afternoon wind direction was considered as a discrete variable. It was pooled in two different wind sectors for every station - with the exception of three sectors for Härkingen - after a careful inspection of the ozone and $\mathrm{NO}_{\mathrm{x}}$ levels for the different wind directions. In addition, the water vapour mixing ratio whose influence on the ozone concentrations is not so obvious (see Sect. 4.1.1), was calculated and averaged for the afternoon hours. Apart from these meteorological parameters, the day of the week (weekday: Monday-Friday, weekend: Saturday-Sunday) was used to account for the weakly cycle of the anthropogenic emissions.

An approximation of the vertical gradient of potential temperature in the boundary layer was calculated for all the stations, by using the afternoon temperature at two different altitude sites in the proximity of the investigated NABEL and OSTLUFT stations. The parameter $T_{p}$, an approximation to the potential temperature, was calculated from the formula of the dry static energy $S$ (Holton, 1992) for every pair of stations:

$T_{p}=S / C_{p}=T+g z / C_{p}$,

where $C_{p}=1005.7 \mathrm{Jkg}^{-1} \mathrm{~K}^{-1}$ (dry air), $g=9.81 \mathrm{~ms}^{-2}, T$ is the temperature (in $\mathrm{K}$ ) and $z$ the altitude (in $\mathrm{m}$ a.s.l.). The 
difference of $T_{p}$ between the low and the elevated station was then used as an indicator for dry static stability. In general there is instability for $\partial T_{p} / \partial z<0$ (i.e. $\mathrm{dT}_{p}>0$ ) and stability for $\partial T_{p} / \partial z>0$ (i.e. $\mathrm{dT}_{p}<0$ ), so higher instability is expected for higher values of $\mathrm{dT}_{p}$. The interpretation of the influence of this parameter on the ozone concentrations should be done depending on both the season and the character (polluted or rural) of the considered station.

Two parameters which affect the vertical mixing, the dilution of primary pollutants and the deposition of ozone within the convective boundary layer (CBL) were calculated daily from the 12:00 UTC radiosoundings at Payerne: the Convective Available Potential Energy (CAPE) and the mixing height, which was determined by a simple parcel method (Seibert et al., 2000). The parameters precipitation, close lightning and distant lighting were used to give account for the effect of thunderstorms on the dilution of pollutants. After thunderstorms, the troposphere is usually rather well mixed and the ozone concentrations might reflect similar conditions to background at some stations. In general, the maximum ozone concentrations on a specific day are not only determined by the meteorology on that day but also by the concentrations and meteorology on the previous day. To take into account the meteorology on the previous day, especially the mixing conditions, the absence/occurrence of precipitation and lightning as well as CAPE were used both on the investigated day and on the previous day.

In addition, two parameters from the Alpine Weather Statistics AWS (Wanner et al., 1998) were also used to account for the ozone variations connected with the frontal passages and the synoptic situation. The parameter "number of days after front" was calculated, using the classes 18 and 21 of the AWS, which indicate the presence/absence of a frontal passage - warm front, cold front or occlusion - in Zürich on the investigated day. The air is usually well mixed after a frontal passage, and it might be expected that the ozone levels build up day by day in summer whereas ozone is more and more depleted under stable conditions in winter. As the effect on the ozone concentrations is more important on the first days, we treated all the days after day 6 in the same way as day 6. Therefore this parameter has 7 possible values: 0 , $1,2,3,4,5,6$. The parameter "synoptic group" is a discrete variable that describes 8 different synoptic situations: 3 convective types (anticyclonic, cyclonic and indifferent), 4 advective types based on the $500 \mathrm{hPa}$ wind direction (north, east, south and west) and mixed conditions. Stable situations ("anticyclonic") are connected with suppressed vertical mixing and stagnation of the air masses. The types "cyclonic", "mixed" and the advective types are usually related to higher vertical mixing and thus favour the dilution of primary pollutants. The influence of this parameter on the surface ozone concentrations at 6 NABEL sites was previously investigated in Brönnimann et al. (2000).

\section{Statistical method}

In this study we used a multiple linear model in order to describe the influence of the meteorological variability on the daily maximum ozone (and $\mathrm{O}_{\mathrm{x}}$ ) concentrations at the individual stations. For the selection of the meteorological parameters explaining most of the variability in the daily ozone maxima we used an analysis of covariance (ANCOVA), which allows to include both continuous and discrete variables. All the parameters introduced in Sect. 2.2. were initially used in ANCOVA (for a summary see Table 2). The main assumptions of the model are that there is a true underlying linear relationship, that the residuals are mutually independent with constant variance (homocedasticity) and that the residuals are normally distributed. The meteorological adjustment of the daily ozone maxima and the calculations of the trends of adjusted daily ozone maxima during the 19922002 period were performed for each station and season separately: spring (MAM), summer (JJA), autumn (SON) and winter (DJF). The winter periods were defined as December 1992 to February 1993, ..., December 2002 to February 2003. The years 2000 and 2001 were excluded from the analysis for Lägeren due to missing ozone or meteorological data, mainly as a consequence of destroyed facilities caused by a severe storm.

Although the use of many meteorological parameters increases the explained variance, those individual parameters are often correlated to each other, so that irrelevant relations between the meteorological variables and ozone might be introduced if all those variables were kept in the final model. As already mentioned, all the variables from Table 2 were initially introduced in a multiple linear model separately for each station and season:

$\mathrm{O}_{3}$ (measured $)=a_{1} A_{1}+a_{2} A_{2}+\ldots$

$+b_{11}+b_{12}+b_{13}+\ldots+b_{21}+b_{22}+\ldots+c+\varepsilon$,

where

$A_{1}, A_{2}, \ldots$ : continuous variables;

$a_{1}, a_{2}, \ldots$ : coefficients of the continuous variables;

$b_{11}, b_{12}, b_{13}, \ldots, b_{21}, b_{22}, \ldots$ : coefficients or "treatment effects" of the discrete variables $B_{1}, B_{2}, \ldots$;

$c$ : intercept;

$\varepsilon$ : random error.

A backward elimination procedure performed with the software R (R Development Core Team, 2003) removed the least important predictor variables in different steps. For that purpose, at every step ANCOVA used the F statistics to provide the $p$-values for the different variables, and the explanatory variable with the highest $\mathrm{p}$-value (maximum likelihood of having a null coefficient and thus lowest effect on the daily ozone maxima) was removed from the model. A stringent stopping criterion $\left(\mathrm{p}<10^{-8}\right)$ was chosen so that a consistent and not too large set of variables could explain a large fraction of the variance in most of the cases. After several iterations, only the variables satisfying the stopping criterion 
Table 2. Number of stations (out of 12) at which each parameter was selected per season after some ANCOVA iterations. Numbers in italic indicate that the variable was selected for 5 or 6 stations (more than $1 / 3$ of the stations). Numbers in bold indicate that the variable was selected at least for 7 stations (more than half the stations). "N" denotes the seasons in which the variable was not used.

\begin{tabular}{|c|c|c|c|c|c|}
\hline Variable & Definition & Spring & Summer & Autumn & Winter \\
\hline $\mathrm{aT}^{2}(\mathrm{aT})^{(\mathrm{a})}$ & afternoon temperature & 12 & 12 & 12 & 4 \\
\hline $\mathrm{aRad}$ & afternoon global radiation & 2 & 0 & 6 & 12 \\
\hline $\mathrm{mRad}$ & morning global radiation & 9 & 8 & 1 & 0 \\
\hline aMR & afternoon water vapour mixing ratio & 9 & 5 & 9 & 5 \\
\hline aSun & afternoon sunshine duration & 1 & 0 & 3 & 0 \\
\hline mSun & morning sunshine duration & 2 & 1 & 1 & 1 \\
\hline aWspeed & afternoon wind speed & 2 & 1 & 5 & 9 \\
\hline mWspeed & morning wind speed & 0 & 1 & 4 & 3 \\
\hline $\operatorname{aWdir}(\mathrm{c})$ & afternoon wind direction & 3 & 2 & 5 & 4 \\
\hline CBL & CBL mixing height & 1 & 0 & 0 & 1 \\
\hline CAPE & Convective Available Potential Energy & 0 & 0 & 3 & $\mathrm{~N}$ \\
\hline pCAPE & CAPE (on the previous day) & 0 & 0 & 0 & $\mathrm{~N}$ \\
\hline $\mathrm{dTp}^{(\mathrm{b})}$ & vertical gradient of potential temperature in the afternoon & 1 & 0 & 9 & 9 \\
\hline Precip $^{(c)}$ & Precipitation on the investigated day & 0 & 0 & 7 & 5 \\
\hline pPrecip $^{(c)}$ & precipitation on the previous day & 0 & 0 & 0 & 0 \\
\hline dLightning $^{(c)}$ & distant lightning on the investigated day & 2 & 2 & 0 & 2 \\
\hline pdLigthning $(\mathrm{c})$ & distant lightning on the previous day & 0 & 0 & 0 & 0 \\
\hline cLightning $^{(c)}$ & close lightning on the investigated day & 0 & 0 & 0 & 0 \\
\hline pcLightning $(\mathrm{c})$ & close lightning on the previous day & 0 & 0 & 0 & 0 \\
\hline Synoptic $^{(c)}$ & synoptic group from the AWS & 0 & 0 & 0 & 0 \\
\hline $\mathrm{ndF}$ & number of days after a frontal passage & 0 & 9 & 0 & 7 \\
\hline wd (c) & day of the week & 4 & 0 & 7 & 6 \\
\hline
\end{tabular}

Sunshine duration as well as close and distant lighting were taken from the MeteoSwiss ANETZ stations Basel-Binningen (for ozone site BAS), Kloten (DUE), Wynau (HAE), Lägeren (LAE), Pully (LAU), Payerne (PAY), Sion (SIO), Tänikon (TAE and WEE), Zürich-SMA (ZUE and STA) and Reckenhold (WAL).

(a) Either the afternoon temperature or the square of the afternoon temperature was used in the model depending on which one was able to explain more variance.

(b) The low altitude ANETZ stations used for the calculation of dTp are Basel-Binningen (for BAS), Zürich-SMA (LAE, ZUE and STA), Payerne (PAY), Sion (SIO), Tänikon (TAE), Reckenhold (WAL) and Güttingen (WEE). For the NABEL stations DUE, HAE and LAU the temperature at low-altitude was taken from the stations themselves. The high altitude ANETZ stations used for the calculation of dTp are Lägeren (for BAS, DUE, HAE, LAE, TAE, ZUE, WAL, STA and WEE) and Montana (SIO). For LAU and PAY the temperature at highaltitude was taken from the NABEL station at Chaumont.

(c) Discrete variables.

$\mathrm{p}<10^{-8}$ were finally included into the multiple linear model (Eq. 2) for each station and season. Other possible stopping criteria, such us stopping the iterations when the explained variance decreases more than a prescribed value (e.g. 1\%) after removing a certain variable from the model, can be found in the statistical literature (e.g. Wilks, 1995). A careful analysis of the residuals revealed that the assumptions of ANCOVA (linearity, homocedasticity and normality) were not violated.

The predicted (i.e. explained by meteorology) daily ozone maxima can be calculated for each station and season with the selected variables and the coefficients obtained from Eq. (2), and the daily ozone maxima can be adjusted for meteorological effects:

$\mathrm{O}_{3}$ (adjusted) $=$ mean $\mathrm{O}_{3}+\left[\mathrm{O}_{3}\right.$ (measured $)-\mathrm{O}_{3}$ (predicted $\left.)\right]$, where mean $\mathrm{O}_{3}$ : mean of all the considered daily maximum ozone concentrations measured in the investigated period spring, summer, autumn or winter of 1992-2002; $\mathrm{O}_{3}$ (measured): daily maxima of the measured ozone concentrations in the investigated period; $\mathrm{O}_{3}$ (predicted): modelled daily maximum ozone concentrations calculated with Eq. (2) for the investigated period

The adjusted daily ozone maxima are thus calculated in Eq. (3) as the mean of the daily ozone maxima in the investigated period plus the residuals of the model (Eq. 2).

The trends of the measured and adjusted daily ozone maxima for the 12 stations and 4 seasons individually can be given by the slopes of the simple linear regression of the respective yearly median of the daily ozone maxima against 
the year Y:

yearly median $\left[\mathrm{O}_{3}\right.$ (measured) $]=d_{1}+d_{2} Y+\varepsilon$

yearly median $\left[\mathrm{O}_{3}\right.$ (adjusted) $]=e_{1}+e_{2} Y+\varepsilon$.

Each individual yearly seasonal median was considered only if at least 60 daily values were available in the respective year and season to ensure a representative sample size. By using just one value - the yearly median of the daily maximum ozone concentrations within the same season - per year one can avoid having to take into account the effect of the serial correlation of daily values on the estimation of the standard errors of the coefficients, the number of degrees of freedom and thus the confidence intervals for the slope. Other solutions to the problem of the serial correlation such as reducing the sample size or using autoregressive movingaverage (ARMA) models can be found in Wilks (1995) and von Storch and Zwiers (1999).

The procedure explained in this section was also used for both the meteorological adjustment of the daily $\mathrm{O}_{\mathrm{x}}$ maxima and the calculation of the trends of their yearly seasonal medians. In addition, three slightly different models for the calculation of the daily $\mathrm{O}_{3}$ maxima trends were investigated. These models and their results will be presented in Sect. 4.3.

\section{Results and discussion}

\subsection{Meteorological adjustment of daily ozone maxima}

\subsubsection{Influence of meteorological variability on daily ozone maxima}

Table 2 shows all the variables that were initially included in the model as well as the number of stations per season at which they were selected by ANCOVA after some iterations (stopping criterion: $\mathrm{p}<10^{-8}$ ). Some of the variables like the mixing height or CAPE derived from the radiosoundings, lightning, precipitation on the previous day, synoptic group from the AWS or sunshine duration were not incorporated into the final model in most of the cases. Either there is a weak dependence of the daily surface ozone maxima on these parameters or the information given by them was already explained by other meteorological variables.

All the variables selected by the model for more than half the stations within the same season are included in Table 3. During the warm seasons the most important explanatory parameters are those that can be related to the chemical ozone production. In particular, the square of the afternoon temperature and the morning global radiation presented a positive correlation with daily ozone maxima both in summer and in spring. In general, under typical summer smog conditions the daily maximum ozone concentrations and temperature are well correlated (e.g. Neftel et al., 2002; Weber and Prévôt, 2002). High temperatures are usually associated
Table 3. Most important explanatory variables for each season.

\begin{tabular}{cccc}
\hline Spring & Summer & Autumn & Winter \\
\hline $\mathrm{aT}^{2}(+)$ & $\mathrm{aT}^{2}(+)$ & $\mathrm{aT}^{2}(+)$ & $\mathrm{aRad}(+)$ \\
$\mathrm{aMR}(-)$ & $\mathrm{ndF}(+)$ & $\mathrm{aMR}(-)$ & $\mathrm{aWspeed}(+)$ \\
$\operatorname{mRad}(+)$ & $\operatorname{mRad}(+)$ & $\mathrm{dTp}(+)$ & $\mathrm{dTp}(+)$ \\
& & Precip (+) & $\operatorname{ndF}(-)$ \\
& & $\operatorname{wd}(+)$ & \\
\hline
\end{tabular}

$\mathrm{aT}^{2}:$ square of the afternoon mean temperature $\left({ }^{\circ} \mathrm{C}^{2}\right)$

aMR: afternoon water vapour mixing ratio $(\mathrm{g} / \mathrm{kg})$

mRad: morning global radiation $\left(\mathrm{W} / \mathrm{m}^{2}\right)$

aRad: afternoon global radiation $\left(\mathrm{W} / \mathrm{m}^{2}\right)$

ndF: number of days after a frontal passage

$\mathrm{dTp}$ : vertical gradient of potential temperature in the afternoon $\left({ }^{\circ} \mathrm{C}\right)$

aWspeed: afternoon averaged wind speed $(\mathrm{m} / \mathrm{s})$

Precip: occurrence/absence of precipitation

wd: day of the week (weekday or weekend)

$(+) /(-)$ means that ozone is enhanced/reduced for higher values of temperature, global radiation, water vapour mixing ratio or wind speed

Precip (+), wd (+), dTp (+): enhanced ozone for days with precipitation, for weekends and for instability, respectively

$\mathrm{ndF}(+/-)$ : increased/decreased ozone on the following days after a frontal passage

with high radiation and stagnation of the air masses, and both the biogenic emissions and evaporative emissions of anthropogenic VOCs increase at high temperatures. In addition, the enhanced thermal decomposition of peroxyacyl nitrates (PANs) at high temperatures yields higher ozone production, as pointed out in some model studies (Sillman and Samson, 1995; Vogel et al., 1999; Baertsch-Ritter et al., 2004). As expected we found a positive correlation between global radiation and the ozone concentrations during the warm seasons, as the photolysis of $\mathrm{NO}_{2}$ and other compounds like $\mathrm{O}_{3}$, carbonyls and HONO leads to the formation of radicals with subsequent involvement in ozone production. It is interesting that the morning radiation and not the afternoon radiation was kept in the final model. This could be partly due to the fact that on fair weather days cumulus clouds often develop in the late afternoon when most of the daily ozone production has already taken place.

In winter, the most important explanatory variables are the ones influencing the vertical mixing and thus the ozone destruction by titration with $\mathrm{NO}$ and dry deposition. Less ozone destruction and thus higher ozone concentrations are expected for high afternoon radiation, high wind speed and instability as they favour vertical mixing. In addition, the supply of ozone from the elevated reservoir layer might be enhanced under good mixing conditions. The model also predicts that in autumn the ozone concentrations are enhanced 
Table 4. Seasonal averages of the explained variance and number of predictors selected per station in the meteorological adjustment (2), MSE ${ }^{(*)}$ of the regressions of the yearly median of measured (4) and meteorologically adjusted (5) ozone, and MSE ratios - i.e. MSE $\mathrm{adj}_{\mathrm{aS}} / \mathrm{MS}_{\text {meas }}$ - for the 12 stations used in the analysis.

\begin{tabular}{cccccc}
\hline & Expl. Var. (\%) & predictors & MSE $_{\text {meas }}$ & MSE $_{\text {adj }}$ & MSE ratio $^{(* *)}$ \\
\hline Spring & 64.9 & 4.0 & 9.55 & 4.33 & 0.49 \\
Summer & 71.0 & 3.4 & 11.88 & 3.83 & 0.40 \\
Autumn & 71.9 & 6.0 & 7.77 & 3.02 & 0.50 \\
Winter & 60.2 & 5.7 & 25.05 & 2.94 & 0.15 \\
\hline
\end{tabular}

${ }^{(*)}$ MSE is an estimate of the variance of the vertical scatter around the fitted line. MSE is given by

$\mathrm{MSE}=\frac{\mathrm{SSE}}{n-2}$,

where SSE is the sum of squared errors in the regressions (4) and (5), and $n$ is the sample size (usually n=11, i.e. 11 years from 1992 to 2002).

(**) The MSE ratio was calculated for each station and season and then averaged for the 12 stations within the same season.

during situations with more vertical mixing and lower primary pollutant concentrations: higher afternoon temperature, instability, precipitation and weekends. Both in autumn and winter, ozone production at higher temperatures or higher radiation might contribute to some extent to the meteorological variability. This is more likely in the autumn season, in which the square of the afternoon temperature is significant for all stations (see Table 2).

The number of days after a frontal passage influences the ozone concentrations in a different way depending on the season: in summer the first days following a frontal passage are usually accompanied by an increase in temperature and more stagnation of the air mass, leading to higher ozone concentrations day after day; the opposite effect can be observed in winter as the stability favours the ozone loss by titration and dry deposition. The reasons for the negative dependence of ozone on the water vapour mixing ratio in spring and autumn are not so obvious, because high water vapour mixing ratios enhance the production of $\mathrm{OH}$ radicals yielding higher ozone concentrations in the high- $\mathrm{NO}_{\mathrm{x}}$ regime (Vogel et al., 1999). However, low water vapour might also be connected to less cloudiness and to more vertical mixing.

It is interesting to compare the parameters considered in this study with those from previous analyses. Thompson et al. (2001) summarized the meteorological variables used in the literature for the statistical modelling of ozone. Surface temperature, wind speed and direction, and humidity were included in most models, while solar radiation and pressure were often available but not incorporated into the final models. In contrast, in our study the wind speed and direction were significant at few sites in the warm season although they were more significant in autumn and winter. Moreover, the morning global radiation and the afternoon global radiation were included in the final model for more than half the stations during the warm and cold seasons, respectively (see Ta- ble 2). Brönnimann et al. (2002) considered most of the main parameters used in our analysis and former studies - afternoon mean temperature, global radiation, wind direction and wind speed, relative humidity (similar to water vapour mixing ratio, used in our analysis), or day of week - for a regression model of the afternoon ozone peaks in summer (AprilSeptember) at 13 NABEL sites. They also included some circulation fields - high or low pressure anomalies, zonal flow anomalies and meridional flow anomalies - in their model to account for synoptic scale ozone variations. In addition, they used gradients of both temperature (similar to the parameter "dTp" used in this study) and water vapour mixing ratio at different levels as indicators of stability and air mass changes within and above the boundary layer. However, they eliminated both the circulation fields and the vertical gradients in a second model because of a difficult comparison of results between different sites. Similarly, we used the parameter synoptic group to account for synoptic scale ozone variations although this parameter was not significant in most cases. Our analysis also considered some variables that can be related to stability like lightning, precipitation and two parameters derived from atmospheric soundings (CAPE and mixing height), although they were not significant in most cases either. Only the precipitation and the vertical gradient of potential temperature were important at a significant number of stations in autumn and winter, as can be seen in Table 2. In contrast to Brönnimann et al. (2002) and our analysis, Kuebler et al. (2001) first removed the long-term trend as well as the seasonal and weekly variations in their analysis of the summer (May-October) peak ozone concentrations at 12 NABEL sites. As a consequence, only three meteorological parameters - the afternoon mean temperature, the daily solar radiation and the afternoon mean wind speed - were needed to remove the residual short-term variations by using a multiple linear regression model. Unlike Kuebler et 
al. (2001) and Brönnimann et al. (2002) that focused on the trend analysis of summer smog ozone in Switzerland, this study has analysed the variability of daily ozone maxima in the four seasons. Our study has also found that the number of days after a frontal passage, variable not considered in former studies, is important to account for the ozone generation (summer months) or destruction (winter months) after a frontal passage.

\subsubsection{Model performance}

The explained variance averaged over all stations ranged from $60.2 \%$ in winter to $71.9 \%$ in autumn (see Table 4 ). In general, the number of significant explanatory variables was higher in the cold months, due to the importance of local effects in winter - on average 5.7 predictors were used at every station for the meteorological adjustment of daily ozone maxima during this season - and the more variable meteorology in autumn - on average 6 predictors were needed. In contrast, most of the variability in the summer daily $\mathrm{O}_{3}$ maxima was explained by the afternoon temperature, the morning global radiation and the number of days after front (see Tables 2 and 3). On average only 3.4 parameters were needed in summer and 4 in spring.

Another way of assessing the model performance is to test if the year-to-year variability in the daily maximum ozone concentrations is effectively reduced after the meteorological adjustment. For that purpose, we calculated the meansquared error (MSE) of the regressions of the yearly seasonal medians of both the measured and adjusted daily ozone maxima against the year (Eqs. 4 and 5), giving $\mathrm{MSE}_{\text {meas }}$ and $\mathrm{MSE}_{\mathrm{adj}}$, respectively. The mean-squared error is given by

$\mathrm{MSE}=\frac{\mathrm{SSE}}{n-2}$,

where SSE is the sum of squared errors in a simple linear regression and $n$ is the sample size. This parameter indicates the degree to which the distribution of residuals clusters tightly (small MSE) or spreads widely (large MSE) around the regression line (Wilks, 1995). $\mathrm{MSE}_{\text {meas }}$ and $\mathrm{MSE}_{\text {adj }}$ were calculated for each station and season, and their seasonal means are given in Table 4. There is high variability in the yearly medians of the measured daily ozone maxima for most of the stations and seasons (see the high values of the seasonal averages of $\mathrm{MSE}_{\text {meas }}$ in Table 4). This variability is reduced after the meteorological adjustment as can be seen from the lower values of $\mathrm{MSE}_{\text {adj }}$ and thus low $\left(\mathrm{MSE}_{\mathrm{adj}} / \mathrm{MSE}_{\text {meas }}\right)$ ratios. On average, after the meteorological adjustment MSE is reduced by $85 \%$ in winter, $60 \%$ in summer, and 50\% in autumn and spring. At Tänikon as an example the yearly medians of the daily maximum ozone concentrations usually lie closer to the trend line after the meteorological adjustment (Fig. 2).
TAE Spring
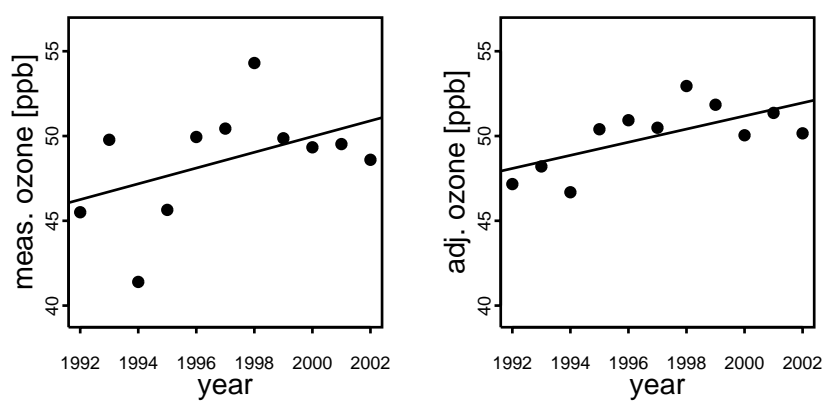

TAE Summer
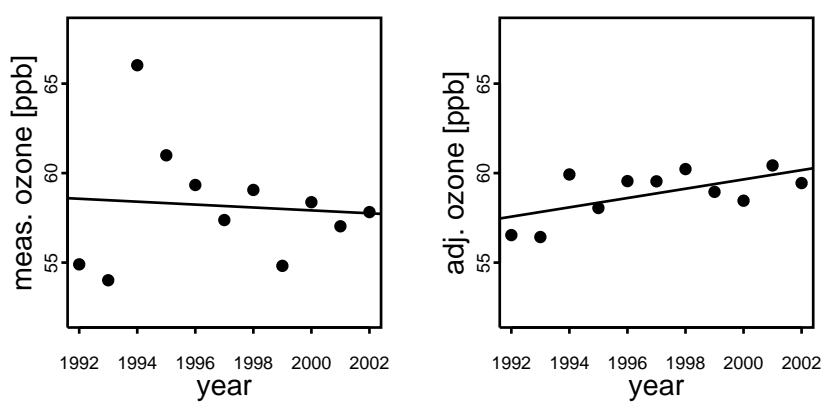

TAE Autumn

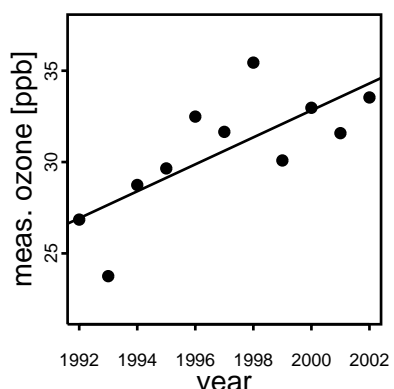

TAE Winter
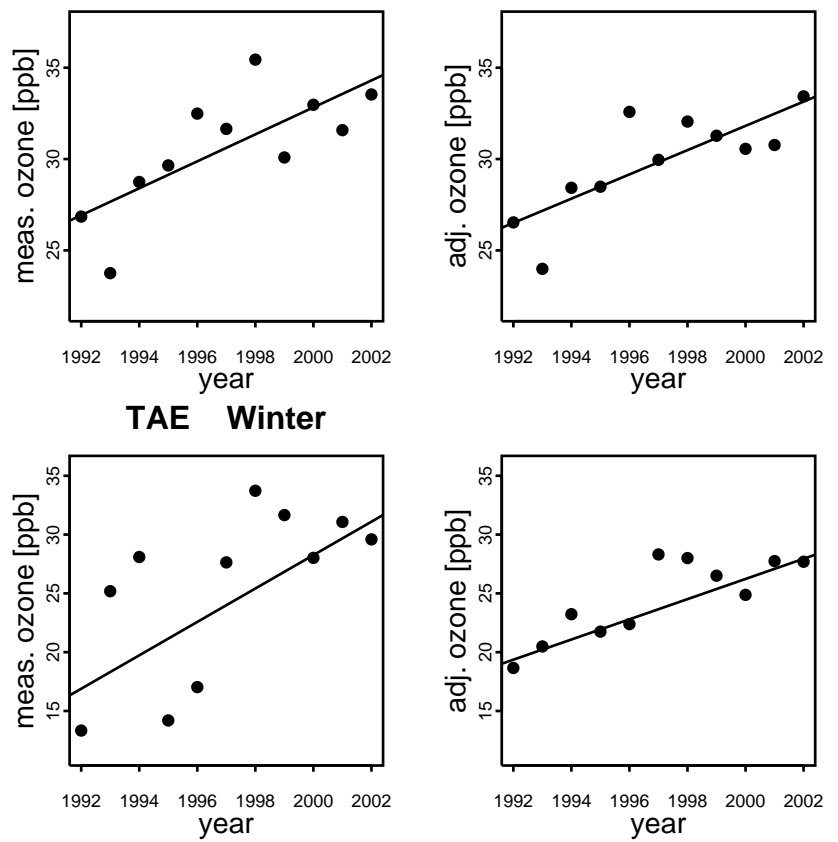

Fig. 2. Yearly medians of the measured daily ozone maxima and meteorologically adjusted daily ozone maxima at Tänikon for all seasons during 1992-2002. The calculated MSE ratio $\left(\mathrm{MSE}_{\mathrm{adj}} / \mathrm{MSE}_{\text {meas }}\right)$ for this station is 0.24 in spring, 0.10 in summer, 0.60 in autumn and 0.12 in winter. 

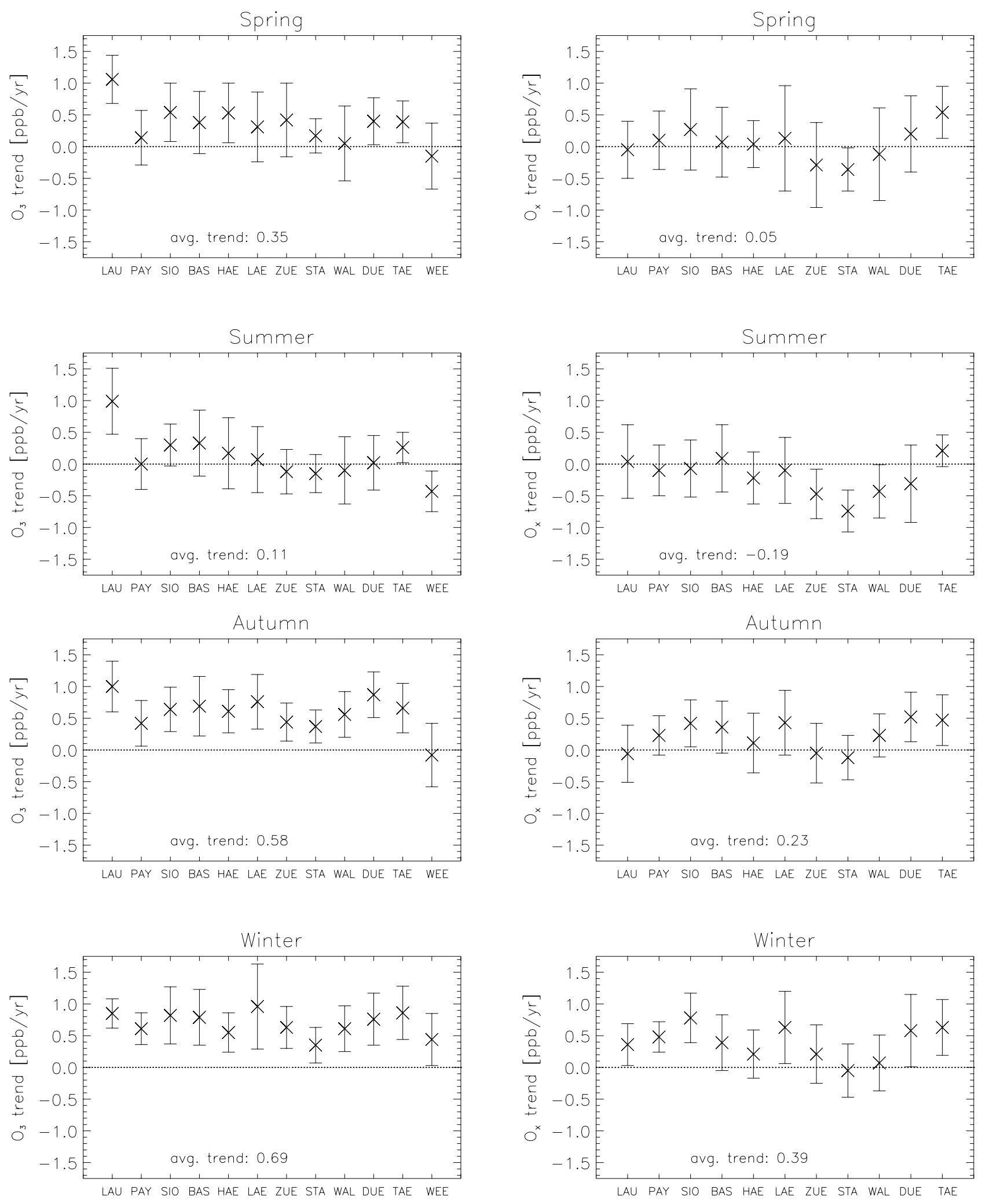

Fig. 3. Trends of the seasonal medians of the meteorologically adjusted daily maximum $\mathrm{O}_{3}$ (left) and $\mathrm{O}_{\mathrm{x}}$ (right) concentrations during 1992-2002. Uncertainty estimates represent 95\% confidence intervals. The averaged trend for all the stations in every season is shown at the lower part of each plot. Station codes (see corresponding names in Table 1) on the $\mathrm{x}$-axis are ordered according to their geographical longitude from West to East. The $\mathrm{O}_{\mathrm{x}}$ trend was not calculated for Weerswilen (WEE) as there were no $\mathrm{NO}_{\mathrm{x}}$ measurements at this station. 

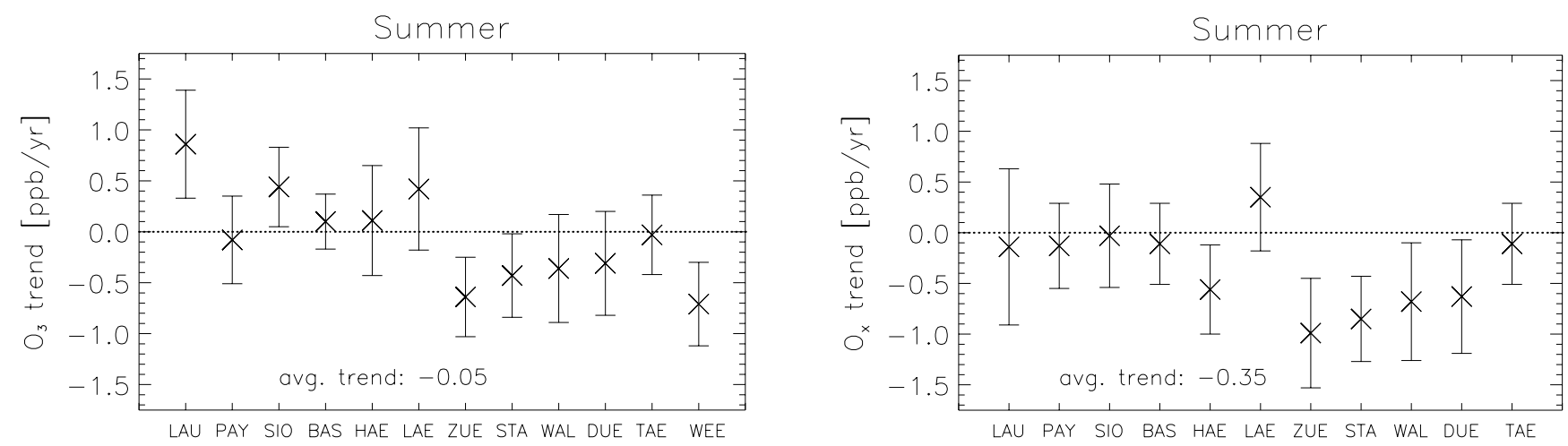

Fig. 4. Trends of the 90 th percentiles of the meteorologically adjusted daily maximum $\mathrm{O}_{3}$ (left) and $\mathrm{O}_{\mathrm{x}}$ (right) concentrations during summer 1992-2002. Uncertainty estimates represent $95 \%$ confidence intervals.

4.2 Trends of meteorologically adjusted daily $\mathrm{O}_{3}$ and $\mathrm{O}_{\mathrm{x}}$ maxima

The trends of the seasonal medians of adjusted daily $\mathrm{O}_{3}$ maxima - calculated with the model (Eq. 5) - and $\mathrm{O}_{\mathrm{x}}$ maxima - calculated analogously - for each station and season are shown in the left- and right-hand side plots of Fig. 3, respectively. The uncertainty estimates in the plots represent the 95\% confidence intervals for those trends.

The absence of negative trends for daily ozone maxima at most stations in spring and summer, seasons in which the main driving mechanism is photochemical production, suggests that the emission reductions of primary pollutants during the $90 \mathrm{~s}-39 \%$ for $\mathrm{NO}_{\mathrm{x}}$ and $49 \%$ for NMVOC in Switzerland during the 1990-2002 period (Vestreng et al., 2004) - were insufficient to significantly reduce the daily maximum ozone concentrations. This was previously found in Kuebler et al. (2001) for the high percentiles of ozone in summer (May-October) 1985-1998. At the 6 most polluted stations used in the analysis (those with the highest $\mathrm{NO}_{\mathrm{x}}$ levels in Table 1), we observed an average decrease in the measured afternoon $\mathrm{NO}_{\mathrm{x}}$ concentrations of $30 \%$ in summer and 35\% in winter during the 1992-2002 period. Positive although not statistically significant $\mathrm{O}_{3}$ trends were observed in summer, except for four stations in the region around Zürich (Zürich-Kaserne, Zürich-Stampfenbach, Wallisellen and Weerswilen). The positive $\mathrm{O}_{3}$ trends might be related to the lower effect of the $\mathrm{O}_{3}$ loss by titration through $\mathrm{NO}$ as a consequence of the decreased emissions of primary pollutants during the 90s. The effect of titration is especially important at the most polluted sites. On average, the $\mathrm{O}_{\mathrm{x}}$ trends are around $0.3 \mathrm{ppb} \mathrm{yr}^{-1}$ lower than the $\mathrm{O}_{3}$ trends for all stations and seasons, which confirms that the calculated $\mathrm{O}_{3}$ trends were affected by the reduced effect of titration. However, except for the mentioned stations in the region around Zürich, the $\mathrm{O}_{\mathrm{x}}$ trends are slightly negative or positive but not significant in summer. The trend analysis of the seasonal 90th percentiles of the meteorologically ad- justed daily $\mathrm{O}_{3}$ and $\mathrm{O}_{\mathrm{x}}$ maxima (Fig. 4) provided additional information: downward trends in summer $\mathrm{O}_{\mathrm{x}}$ were found for 5 stations in the region around Zürich (on average $-0.73 \mathrm{ppb}$ $\mathrm{yr}^{-1}$ for Härkingen, Zürich-Kaserne, Zürich-Stampfenbach, Wallisellen and Dübendorf) as well as a significant downward trend in summer $\mathrm{O}_{3}$ observed at Weerswilen (the $\mathrm{O}_{x}$ trend was not calculated for this station as no $\mathrm{NO}_{\mathrm{x}}$ measurements were available). The summer $\mathrm{O}_{3}$ and $\mathrm{O}_{x}$ trends at Lägeren are higher for the 90th percentiles than for the medians, although we should keep in mind that the trends calculated at this station can be affected by the exclusion of two years from the analysis (2000 and 2001) as explained in Sect. 3. As the region around Zürich is the most densely populated and industrialised area in Switzerland, the local production is contributing more to the ozone concentrations than in other areas. The decrease of the precursor emissions thus might have led to a significant decrease of ozone only in this area, and that decrease is more pronounced for the highest ozone peaks on summer smog days. Considering the results found for all the analysed stations, the lower regional ozone production due to the decreased emissions of ozone precursors might have been compensated by increased large-scale background or other processes.

Significantly positive trends of the medians of adjusted daily ozone maxima were found for all the stations in autumn and winter - except at Weerswilen in autumn -, probably due to the reduced effect of the titration on the ozone concentrations. As already mentioned, this effect could be confirmed by the lower trends of daily $\mathrm{O}_{\mathrm{x}}$ maxima (on average $0.39 \mathrm{ppb} \mathrm{yr}^{-1}$ in winter) compared to the trends of daily ozone maxima (on average $0.69 \mathrm{ppb} \mathrm{yr}^{-1}$ in winter). The $\mathrm{O}_{\mathrm{x}}$ trends are also significantly positive at most of the stations, suggesting an increase in background ozone as already proposed by Brönnimann et al. (2002). There are evidences for an increase of the mean ozone concentrations in Europe at high-altitude sites (e.g. for Zugspitze see Guicherit and Roemer, 2000, and TOR-2, 2003), at lower altitude sites under selected background conditions (e.g. for Switzerland 
see Brönnimann et al., 2000) or at remote sites (e.g. for Mace Head see Simmonds et al., 2004). Nevertheless, the causes for this increase need further study since "background ozone" is influenced by different chemical and dynamical processes on different scales, such as photochemistry on a continental and on a hemispheric scale as well as large- or regional scale horizontal and vertical transport.

Lausanne, the most polluted site analysed in this study, is the only station that presents significantly positive trends of adjusted daily ozone maxima during all seasons. This is most probably due to the reduced effect of the $\mathrm{O}_{3}$ titration by NO. In fact, the $\mathrm{O}_{\mathrm{x}}$ trends at this station are very close to zero in all seasons except in winter $\left(0.49 \pm 0.32 \mathrm{ppb} \mathrm{yr}^{-1}\right)$. However, when analysing the $\mathrm{O}_{\mathrm{x}}$ trends at such polluted stations like Lausanne and Härkingen, one should take into account that those trends are affected by the trend in $\mathrm{NO}_{2}$ emissions. The dominant $\mathrm{NO}_{\mathrm{x}}$ source in urban locations is road traffic exhaust. Although the $\mathrm{NO}_{2}$ input from direct emission varies from one location to another or from one time to another, as a result of varying vehicle fleet composition and driving speeds, an average figure of approximately $5 \%$ (by volume) of $\mathrm{NO}_{\mathrm{x}}$ emitted in the form of $\mathrm{NO}_{2}$ is often quoted (Clapp and Jenkin, 2001). If we assume that the 5\% value is constant for the studied period, it is possible to estimate the trend of emitted $\mathrm{NO}_{2}$ as the $5 \%$ of the $\mathrm{NO}_{\mathrm{x}}$ trend (in ppb $\mathrm{yr}^{-1}$ ). As an example the calculated trend of $\mathrm{NO}_{\mathrm{x}}$ at Lausanne is around $-4.7 \mathrm{ppb} \mathrm{yr}^{-1}$ (around 44\%, somewhat higher than the 32\% value given by the emission inventory for Switzerland in that period), resulting in a trend of directly emitted $\mathrm{NO}_{2}$ lower

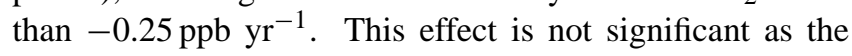
$95 \%$ confidence intervals for the $\mathrm{O}_{\mathrm{x}}$ trends at all sites are always larger than the absolute value of the calculated trends of directly emitted $\mathrm{NO}_{2}$.

\subsection{Robustness of the model}

Three variations of the model described in Sect. 3 were used and their results were compared to those of the first model. This made it possible to investigate the sensitivity of both the meteorological adjustment of daily ozone maxima and the calculated trends of adjusted daily ozone maxima to the model chosen.

As already explained in Sect. 3, the statistical model was optimised so that a consistent and not too large set of explanatory variables was kept in the final model in most cases. Actually, there was high consistency in the selection of explanatory variables for the different sites within the same season although each station presented its own distinctive patterns. A "reduced model" was used to address whether a more limited number of parameters could be consistently used for all the stations within the same season. For that purpose, only the most important explanatory variables in every season - i.e. variables from Table 3 - were included in the model (Eq. 2) for the calculation of the predicted daily ozone maxima at every station and the corresponding sea- sonal trends of adjusted daily ozone maxima were also calculated with Eq. (5). In general, the results obtained with the "reduced model" are very similar those of the first model (see columns "yearly median $\mathrm{O}_{3}$ " and "reduced model" in Table 5) although somewhat poorer - usually lower explained variance, occasionally different trends and sometimes larger confidence intervals - for some stations in some seasons. This suggests that, although it is preferable to use the model described in Sect. 3, the "reduced model" can be used if a simplified and consistent procedure for all stations is wanted.

Finally, in a different approach, the year Y was included as an additional variable together with the rest of the meteorological parameters (those from Table 2) in the multilinear model:

$\mathrm{O}_{3}$ (measured) $=m Y+\alpha_{1} A_{1}+\alpha_{2} A_{2}+\ldots$

$+\beta_{11}+\beta_{12}+\beta_{13}+\ldots+\beta_{21}+\beta_{22}+\ldots+c+\varepsilon$.

As in the meteorological adjustment explained in Sect. 3, a backward elimination procedure was used to remove the least important predictor variables from the model (Eq. 7). For that purpose, the least significant explanatory variable (highest p-value) was also provided by ANCOVA at every step and the same stopping criterion $\left(\mathrm{p}<10^{-8}\right)$ was used. The variable year (Y) was not allowed to be removed from the model (Eq. 7) so that the trend - significant or not - could be calculated. The coefficient $m$ obtained after all the iterations is in this case the new value of the trend and can be compared with the trends $e_{2}$ obtained from Eq. (5) and $f_{2}$ from the linear model:

yearly mean $\left[\mathrm{O}_{3}\right.$ (adjusted) $]=f_{1}+f_{2} Y+\varepsilon$.

For every station and season, very similar explanatory variables were finally kept in the initial meteorological adjustment (Eq. 2) and in the model (Eq. 7). In general, the calculated ozone trends $e_{2}, f_{2}$ and $m$ for each station and season did not differ either. This suggests that the selection of the model is not too critical either for the meteorological adjustment or for the calculation of the trends of daily ozone maxima. A short summary with the comparison of the averaged seasonal trends obtained with the different models is presented in Table 5. However, the model (Eq. 7) presents the drawback that it only gives a value of the trend, whereas the other methods allow for an easier visual inspection of the yearly seasonal medians/means of the adjusted daily ozone maxima. A visual inspection of the fitted linear trend makes it possible to identify years with very high/low ozone maxima that can have a strong impact on the calculation of a linear trend, especially when those years are located at the beginning or end of the considered period. As seen in Sect. 4.1.2, if the regression of the yearly median or yearly mean of daily ozone maxima against the year is used, one can also compare the year-to-year variability (MSE values) of daily ozone maxima before and after the meteorological adjustment. 
Table 5. Averages of the trends in the seasonal medians of adjusted daily ozone maxima calculated with the different models for the 12

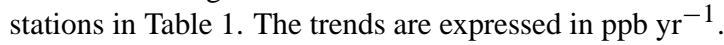

\begin{tabular}{ccccc}
\hline & yearly median $\mathrm{O}_{3}{ }^{(\mathrm{a})}$ & "reduced model"(b) & yearly mean $\mathrm{O}_{3}^{(\mathrm{c})}$ & year in the model \\
\hline spring & 0.35 & 0.38 & 0.29 & 0.31 \\
summer & 0.11 & 0.12 & 0.10 & 0.11 \\
autumn & 0.58 & 0.60 & 0.56 & 0.58 \\
winter & 0.69 & 0.64 & 0.63 & 0.69 \\
\hline
\end{tabular}

(a) The individual trends of the yearly median of daily $\mathrm{O}_{3}$ maxima at every station were calculated with Eq. (5).

(b) For the calculation of the daily $\mathrm{O}_{3}$ maxima trends with the "reduced model" the Eq. (5) was also used but only the most important explanatory variables in every season - i.e. variables from Table 3 - were first consistently introduced in Eq. (2) for the meteorological adjustment of ozone at all the stations.

(c) The individual trends of the yearly mean of daily $\mathrm{O}_{3}$ maxima were calculated with Eq. (8).

(d) The $\mathrm{O}_{3}$ trends calculated with the year included in the model are given by the coefficient of the year in the regression model (Eq. 7).

\section{Analysis of an extreme case: summer 2003}

Summer 2003 was extremely dry and warm in Europe. Based on a reconstruction of monthly and seasonal temperature fields for European land areas back to 1500, Luterbacher et al. (2004) concluded that summer 2003 was very likely warmer than any other summer during the last 500 years. In a large area of central Europe, including Switzerland, the mean summer (June, July and August) temperatures exceeded the 1961-1990 mean by $\sim 3^{\circ} \mathrm{C}$, corresponding to an excess of up to 5 standard deviations of the summer means in that period (Schär et al., 2004). Taking into account the temperature record of the past $\sim 150$ years, such a warm summer is a very rare event, even when the warming in the last decades is considered. The described summer 2003 led to unusually long periods with high ozone concentrations in Switzerland: on average the number of exceedances of the Swiss air quality standard for $1-\mathrm{h}$ mean values $\left(120 \mu \mathrm{g} / \mathrm{m}^{3}\right)$ was up to $700 \mathrm{~h}$, twice as much as in the previous years. Moreover, the 2003 summer mean of the daily ozone maxima at the investigated stations exceeded the 1992-2002 summer mean of daily ozone maxima by more than $15 \mathrm{ppb}$, corresponding to 5 standard deviations of those 1992-2002 summer means, similarly as found for the temperature. The effects of the summer 2003 heat wave were also observed in other European countries. The UK Office for National Statistics reported an excess of 2045 deaths in England and Wales for the period from 4 to 13 August 2003 above the 1998-2002 average for that time of the year. Stedman (2004) estimated that between 423 and 769 of those excess deaths (21-38\% of the total) were associated with the elevated ambient ozone and $\mathrm{PM}_{10}$ concentrations. In a similar study Fischer et al. (2004) found that of an excess of 1000-1400 deaths in the Netherlands during summer 2003 compared to the average summer of 2000 , 400-600 deaths were ozone- and $\mathrm{PM}_{10}$-related.

In order to assess whether the statistical model described in Sect. 3 was able to explain the high ozone concentrations in Switzerland during that extreme summer, the coefficients calculated with Eq. (2) for each station during the period summer 1992-2002 were also used for the calculation of the predicted daily ozone maxima at the corresponding station in summer 2003. The meteorologically adjusted daily ozone maxima for the period summer 1992-2003 were calculated with Eq. (3).

A visual inspection of the yearly medians of the daily ozone maxima at the different stations in summer (Fig. 5) reveals that the very high median of the measured daily maxima in summer 2003 ("meas. ozone" plots) is reduced after the meteorological adjustment ("adj. ozone" plots) for most of the stations, with the exception of Härkingen (polluted station close to a highway), for which the meteorological adjustment was less effective. One reason for this might be that the excess of the mean daily ozone maxima observed at this station in summer 2003 (over $20 \mathrm{ppb}$ and 7 standard deviations higher than in summer 1992-2002) is larger than at the other stations. Not only the medians of the daily maximum ozone concentrations but also the variability of the daily ozone maxima in summer 2003 are consistent with the previous years after adjusting for the meteorological influence. Examples are shown for an urban site - Lausanne - and a rural one - Tänikon - in Fig. 6. Very similar results were obtained for the rest of the stations, again with the exception of Härkingen.

The fact that the meteorological adjustment introduced in Sect. 3 also performs well for an extreme case like that of summer 2003 also indicates that our former conclusions about the main explanatory variables are robust. Considering the afternoon temperature, the number of days after a frontal passage and the morning global radiation for most of the stations (see column "Summer" in Table 2), in combination with only one or a few variables which vary depending on the station (on average only 3.4 predictors are needed, as seen in Table 4), one can explain the meteorological variability of summer daily ozone maxima at different sites north 

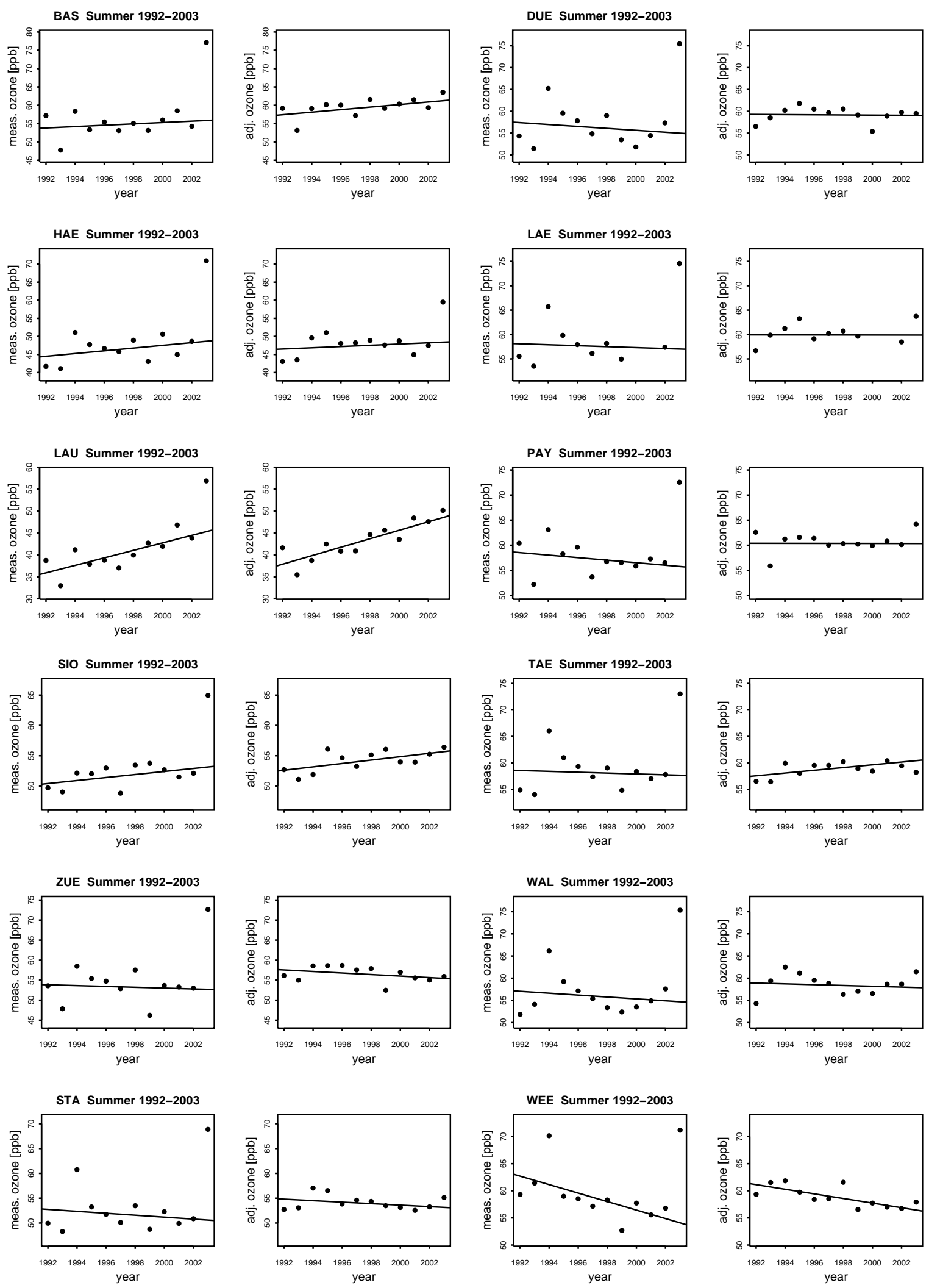

Fig. 5. Yearly medians of the daily ozone maxima at the analysed stations in summer for the 1992-2003 period. For every station the first plot shows the yearly medians of the measured daily ozone maxima and the second plot depicts the yearly medians of the adjusted daily ozone maxima. The trend lines in the plots have been calculated using only summer data from 1992 to 2002. 


\section{LAU Summer 1992-2003}
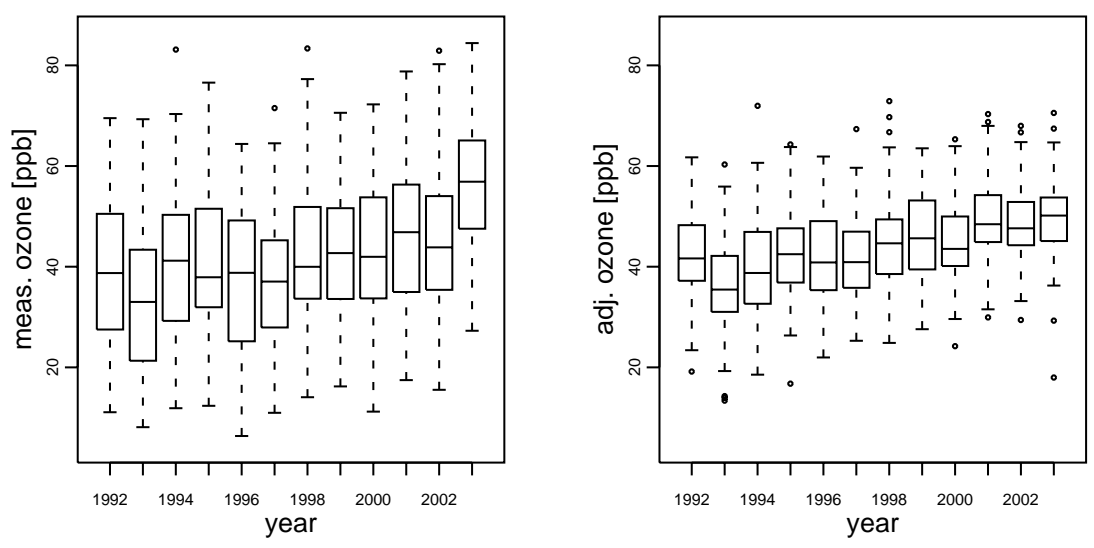

\section{TAE Summer 1992-2003}
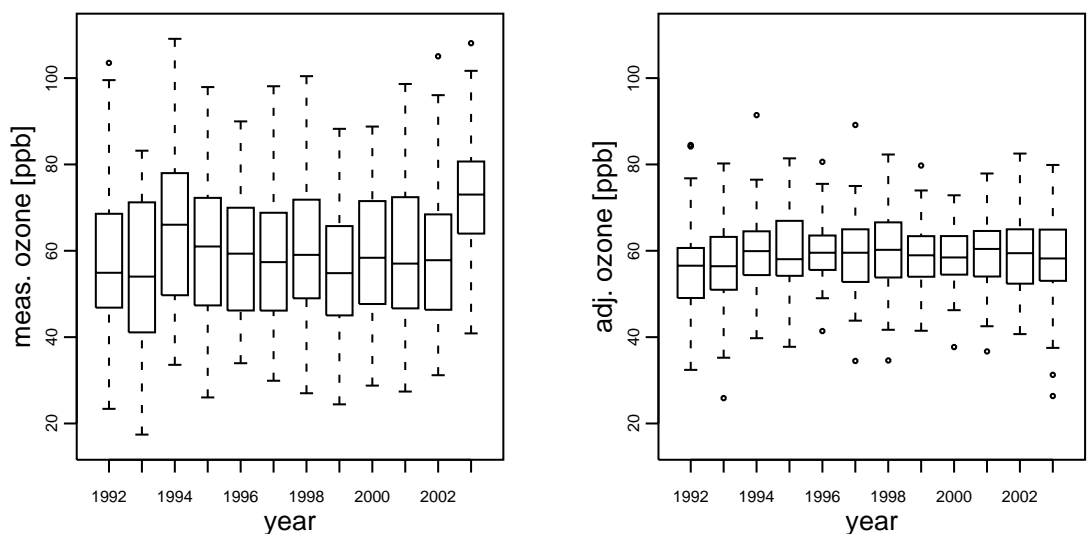

Fig. 6. Boxplots of the measured (left) and meteorologically adjusted (right) daily ozone maxima in summer 1992-2003 for Lausanne (top) and Tänikon (bottom). Each box depicts the central half of the data between the lower quartile $\left(\mathrm{q}_{0.25}\right)$ and the upper quartile $\left(\mathrm{q}_{0.75}\right)$. The line across the box displays the median value $\left(\mathrm{q}_{0.5}\right)$. The whiskers extend from the top and the bottom of the box to depict the extent of the main body of the data. Extreme data values are plotted with a circle.

of the Alps in Switzerland even during this extremely warm summer.

\section{Conclusions}

An analysis of covariance (ANCOVA) has been used to account for the variability of daily ozone maxima at 12 stations north of the Alps in Switzerland during the 1992-2002 period. The analysis has been done separately for each season, motivated by the well known fact that the processes governing the relations between ozone and meteorological parameters differ significantly during the year and can even change sign (Tarasova and Karpetchko, 2003). The analysis of the most important explanatory variables (see Tables 2 and 3) leads to the conclusion that ozone production is the dominant mechanism both in summer and spring, while ozone destruction by titration and dry deposition prevails in winter, as expected. Autumn seems to be an intermediate case, with more variable meteorology, and around 6 parameters are usually needed to account for the meteorological variability of daily ozone maxima in this season compared to the average of 3.5 parameters in summer. In general, similar meteorological variables to those reported in the literature for the meteorological adjustment of ozone in the summer season were found to be significant for the same season in this work. In addition, this analysis found that the number of days after a frontal passage, a variable not considered in previous studies, is important to account for ozone generation in summer and ozone destruction in winter.

Most of the variability in the daily maximum ozone concentrations was explained by ANCOVA, taking into account the meteorological variability on a local, regional and to some extent synoptic scale. On average, the explained variance ranged from $60.2 \%$ in winter to $71.9 \%$ in autumn. The year-to-year variability of the daily ozone maxima was reduced by $85 \%$ in winter, $60 \%$ in summer, and $50 \%$ in autumn and spring after the meteorological adjustment. 
No significant downward trends in either the seasonal medians or the 90th percentiles of daily $\mathrm{O}_{3} / \mathrm{O}_{\mathrm{x}}$ maxima were found for 6 stations in summer. However, 6 sites in the industrialised region around Zürich presented significant downward trends in the summer 90th percentiles of daily $\mathrm{O}_{\mathrm{x}}$ or $\mathrm{O}_{3}$ maxima, which suggests that the precursor emission reductions had at least a significant effect on the highest ozone peaks during summer smog days in this area. At all locations, the decrease in the local production due to the reductions of the precursor emissions $-39 \%$ for $\mathrm{NO}_{\mathrm{x}}$ and $49 \%$ for NMVOC in Switzerland during the 1990-2002 period (Vestreng et al., 2004) - might have been compensated by a background ozone increase. The significantly positive trends of $\mathrm{O}_{3}$ in winter (on average $0.69 \mathrm{ppb} \mathrm{yr}^{-1}$ ) are partially due to the lower titration as a consequence of the decreased emissions, too. The influence of the chemistry on a local and regional scale is lowered if one analyses the $\mathrm{O}_{\mathrm{x}}$ winter trends. The increase of $\mathrm{O}_{\mathrm{x}}$ found for most of the stations in autumn (on average $0.23 \mathrm{ppb} \mathrm{yr}^{-1}$ ) and winter (on average $0.39 \mathrm{ppb} \mathrm{yr}^{-1}$ ) could be due to increasing background ozone levels, in agreement with other studies for Europe (TOR-2 and TROTREP) and Switzerland (Brönnimann et al., 2000, 2002). The causes for this European background increase might be related to intercontinental transport, hemispheric background increase or large-scale meteorological variability not taken into account by local meteorological factors. The impact of some of these processes on the surface ozone variability and trends have been addressed, among others, by Lelieveld and Dentener (2000) and Tarasova et al. (2003).

Finally, summer 2003, the warmest summer in the longterm temperature series available in Switzerland since 1864, was a good opportunity to validate our model. The daily ozone maxima in summer 2003 were on average $15 \mathrm{ppb}$ higher than in summer 1992-2002, corresponding to 5 standard deviations of the summer means of daily ozone maxima in that period. The model used to adjust for meteorological effects was able to lower the daily ozone maxima in that summer to concentrations found in the previous years. Even though an event like that of summer 2003 is statistically extremely unlikely if one takes into account the climate in the last $\sim 150$ years, regional climate model (RCM) simulations in scenarios with increased atmospheric greenhousegas concentrations suggest that such summers might be more frequent in Europe towards the end of the century (Schär et al., 2004). This might lead to a higher occurrence of severe ozone episodes with serious implications for human health (e.g. see Fischer et al., 2004; Stedman, 2004) and ecosystems if the emissions are not significantly reduced.

Acknowledgements. This research was carried out with the financial support of the Swiss Agency for Environment, Forests and Landscape (SAEFL). The meteorological data from ANETZ stations and the Payerne soundings were provided by MeteoSwiss. Ozone and primary pollutants data at Zürich-Stampfenbach, Wallisellen and Weerswilen were provided by OSTLUFT. The authors gratefully acknowledge W. Stahel, B. Tona, J. Maeder and
S. Brönnimann - ETH Zürich - for helpful discussions concerning the statistical methods used. We also thank two anonymous reviewers for their interesting comments, which helped to improve the quality of the manuscript.

Edited by: A. Hofzumahaus

\section{References}

Baertsch-Ritter, N., Keller, J., Dommen, J., and Prévôt, A. S. H.: Effects of various meteorological conditions and spatial emission resolutions on the ozone concentration and $\mathrm{ROG} / \mathrm{NO}_{\mathrm{x}}$ limitation in the Milan area (I), Atmos. Chem. Phys., 4, 423-438, 2004,

SRef-ID: 1680-7324/acp/2004-4-423.

Bloomfield, P. J., Royle, J. A., Steinberg, L. J., and Yang, Q.: Accounting for meteorological effects in measuring urban ozone levels and trends, Atmos. Envir., 30 (17), 3067-3077, 1996.

Brönnimann, S., Schuepbach, E., Zanis, P., Buchmann, B., and Wanner, H.: A climatology of regional background ozone at different elevations in Switzerland (1992-1998), Atmos. Envir., 34, 5191-5198, 2000.

Brönnimann, S., Buchmann, B., and Wanner, H.: Trends in nearsurface ozone concentrations in Switzerland: the 1990s, Atmos. Envir., 36, 2841-2852, 2002.

Clapp, L. J. and Jenkin, M. E.: Analysis of the relationship between ambient levels of $\mathrm{O}_{3}, \mathrm{NO}_{2}$ and $\mathrm{NO}$ as a function of $\mathrm{NO}_{\mathrm{x}}$ in the UK, Atmos. Envir., 35 (36), 6391-6405, 2001.

Cox, W. and Chu, S.: Assessment of interannual ozone variation in urban areas from a climatological perspective, Atmos. Envir., 30, 2615-2625, 1996.

Davis, J. M., Eder, B. K., Nychka, D., and Yang, Q.: Modeling the effects of meteorology on ozone in Houston using cluster analysis and generalized additive models, Atmos. Envir., 32, 25052520, 1998.

Dommen, J., Neftel, A., Sigg, A., and Jacob, D. J.: Ozone and hydrogen peroxide during summer smog episodes over the Swiss Plateau: Measurements and model simulations, J. Geophys. Res., 100, 8953-8966, 1995.

Dommen, J., Prévôt, A. S. H., Hering, A. M., Staffelbach, T., Kok, G. L., and Schillawski, R. D.: Photochemical production and aging of an urban air mass, J. Geophys. Res., 104, 5493-5506, 1999.

Ehhalt, D., Prather, M., Dentener, F., Derwent, R., Dlugokencky, E., Holland, E., Isaksen, I., Katima, J., Kirchhoff, V., Matson, P., Midgley, P., Wang, M., et al.: Atmospheric Chemistry and Greenhouse Gases, in: Climate Change 2001: The Scientific Basis, edited by: Houghton, J. T., Ding, Y., Griggs, D. J., et al., Contribution of Working Group 1 to the Third Assessment Report of the IPCC, 4, 239-288, 2001.

EMPA (Swiss Federal Laboratories for Materials Testing and Research): Technischer Bericht zum Nationalen Beobachtungsnetz Für Luftfremdstoffe (NABEL) 2002, Dübendorf, 2003.

Fischer, P. H., Brunekreef, B., and Lebret, E.: Air pollution related deaths during the 2003 heat wave in the Netherlands, Atmos. Envir. 38, 1083-1085, 2004.

Guicherit, R. and Roemer, M.: Tropospheric ozone trends, Chemosphere - Global Change Science, 2, 167-183, 2000.

Holton, J. R.: An Introduction to Dynamic Meteorology, 3rd edition, Academic Press, 1992. 
Joe, H., Steyn, D. G., and Susko, E.: Analysis of trends in tropospheric ozone in the lower Fraser Valley, British Columbia, Atmos. Envir., 30, 3413-3421, 1996.

Kuebler, J., van den Bergh, H., and Russell, A. G.: Long-term trends of primary and secondary pollutant concentrations in Switzerland and their response to emission controls and economic changes, Atmos. Envir., 35, 1351-1363, 2001.

Lelieveld, J. and Dentener, F. J.: What controls tropospheric ozone?, J. Geophys. Res., 105, 3531-3551, 2000.

Luterbacher, J., Dietrich, D., Xoplaki, E., Grosjean M., and Wanner, H.: European seasonal and annual temperature variability, trends, and extremes since 1500, Science, 303, 1499-1503, 2004.

Monks, P. S., Rickard, A. R., Dentener, F., Jonson, J. E., Lindskog, A., Roemer, M., Schuepbach, E., Friedli, T. K., and Solberg, S.: TROTREP Synthesis and Integration Report, Report to the EU FPV Energy, Environment and Sustainable Development program, European Union, 2003.

Neftel, A., Spirig, C., Prévôt, A. S. H., Furger, M., Stutz, J., Vogel, B., and Hjorth, J.: Sensitivity of photooxidant production in the Milan Basin: An overview of results from a EUROTRAC-2 Limitation of Oxidant Production field experiment, J. Geophys. Res., 107(D22), 8188, doi:10.1029/2001JD001263, 2002.

Ramaswamy, V., Boucher, O., Haigh, J., Hauglustaine, D., Haywood, J., Myhre, G., Nakajima, T., Shi, G. Y., Solomon, S., et al.: Radiative Forcing of Climate Change, edited by: Houghton, J. T., Ding, Y., Griggs, D. J., et al., in: Climate Change 2001: The Scientific Basis, Contribution of Working Group 1 to the Third Assessment Report of the IPCC, 6, 349-416, 2001.

Rao, S., Zurbenko, I., Neagu, R., Porter, S., Ku, J., and Henry, R. F.: Space and Time Scales in Ambient Ozone Data, B. Am. Meteor., 78, 2153-2166, 1997.

R Development Core Team: R: A language and environment for statistical computing, R Foundation for Statistical Computing, Vienna, Austria, http://www.R-project.org, 2003.

Roemer, M.: In search for trends of ozone and precursors, First Progress Report TROTREP, TNO-report R2001/100, 2001a.

Roemer, M.: Trends of ozone and precursors in Europe, Status report TOR-2, Task group 1, TNO-report R2001/244, $2001 \mathrm{~b}$.

Schär, C., Vidale, P. L., Lüthi, D., Frei, C., Häberli, C., Liniger, M. A., and Appenzeller, C.: The role of increasing temperature variability in European summer heatwaves, Nature, 427, 332336, 2004.

Seibert, P., Beyrich, F., Gryning, S. E., Joffre, S., Rasmussen, A., and Tercier, P.: Review and intercomparison of operational methods for the determination of the mixing height, Atmos. Envir., 34 (7), 1001-1027, 2000.

Sillman, S. and Samson, P. J.: Impact of temperature on oxidant photochemistry in urban, polluted and remote environments, J. Geophys. Res., 100, 11 497-11 508, 1995.
Simmonds, P. G., Derwent, R. G., Manning, A. L., and Spain, G.: Significant growth in surface ozone at Mace Head, Ireland, 1987-2003, Atmos. Envir., 38, 4769-4778, 2004.

Staehelin, J., Thudium, J., Buehler, R., Volz-Thomas, A., and Graber, W.: Trends in surface ozone concentrations at Arosa (Switzerland), Atmos. Envir., 28, 75-87, 1994.

Stedman, J. R.: The predicted number of air pollution related deaths in the UK during the August 2003 heatwave, Atmos. Envir., 38, 1087-1090, 2004.

Tarasova, O. A., Elansky, N. F., Kuznetsov, G. I., Kuznetsova, I. N., and Senik, I. A.: Impact of Air Transport on Seasonal Variations and Trends of Surface Ozone at Kislovodsk High Mountain Station, J. Atmos. Chem., 45, 245-259, 2003.

Tarasova, O. A. and Karpetchko, A. Yu.: Accounting for local meteorological effects in the ozone time-series of Lovozero (Kola Peninsula), Atmos. Chem. Phys., 3, 941-949, 2003,

SRef-ID: 1680-7324/acp/2003-3-941.

Thompson, M. L., Reynolds, J., Cox, L. H., Guttorp, P., and Sampson, P. D.: A review of statistical methods for the meteorological adjustment of tropospheric ozone, Atmos. Envir., 35, 617-630, 2001.

TOR-2: Tropospheric Ozone Research, EUROTRAC-2 Subproject Final Report, ISS GSF-National Research Center for Environment and Health, Munich, Germany, 2003.

Vestreng, V., Adams, M., and Goodwin, J.: Inventory Review 2004, Emission Data reported to CLRTAP and under the NEC Directive, EMEP/EEA Joint Review Report, EMEP/MSC-W Note 1/2004, ISSN 0804-2446, 2004.

Vogel, B., Riemer, N., Vogel, H., and Fiedler, F.: Findings on $\mathrm{NO}_{\mathrm{y}}$ as an indicator for ozone sensitivity based on different numerical simulations, J. Geophys. Res., 104, 3605-3620, 1999.

Von Storch, H. and Zwiers, F. W.: Statistical Analysis in Climate Research, Cambridge University Press, 484, 1999.

Wanner, H., Salvisberg, E., Rickli, R., and Schüepp, M.: 50 years of Alpine Weather Statistics (AWS), Meteorologische Zeitschrift, Neue Folge, 7, 99-111, 1998.

Weber, R. O. and Prévôt, A. S. H.: Climatology of ozone transport from the free troposphere into the boundary layer south of the Alps during North Foehn, J. Geophys. Res., 107(D3), 4030, doi:10.1029/2001JD000987, 2002.

Wilks, D. S.: Statistical Methods in the Atmospheric Sciences, Academic Press, San Diego, 1995.

$\mathrm{Xu}$, D., Yap, D., and Taylor, P. A.: Meteorologically adjusted ground level ozone trends in Ontario, Atmos. Envir., 30 (7), 1117-1124, 1996.

Zurbenko, I.: Spectral analysis of nonstationary time series, Int. Stat. R., 59 (2), 163-173, 1991. 